\title{
A Proposed Supergrid Model for National Transmission Network of Pakistan
}

\author{
FAHEEM AKHTER*, ALI ASGHAR MEMON**, AND NOOR NABI SHAIKH** \\ RECEIVED ON 09.03.2016 ACCEPTED ON 16.08.2016 \\ ABSTRACT
}

Pakistan is facing a severe energy crisis of its time with significant generation deficit in recent years. The future plan shows hydro and thermal coal generation as major contributor and Wind power to replace Thermal-oil generation in long run. This paper proposes a Super grid model for the transfer of bulk power from generation station to the load centres, which can provide efficient transmission between generation and load centres and is also adaptive to deal with variations in power from renewable generations. A dynamic simulation analysis is performed on six-terminal MTDC (Multi-Terminal High Voltage Direct Current) system VSC (Voltage Source Converter) based MTDC meshed grid with different control operations. The results show that the proposed super grid model can provide efficient transmission between generation and load centres and it is also adaptive to deal with variation in power from renewable generation.

Key Words: Wind Energy, High Voltage Direct Current Transmission, Super Grid, Control Operations.

\section{INTRODUCTION}

$\mathrm{T}$ The challenges of combating the climate change and continuous increasing demand of electrical energy with fast depletion of primary conventional fuels have transformed the power system from number of isolated country based grids to large integrated regional grids. The centralized generation, which is mostly dependent on the fossil fuels, is being overtaken by the distributed generation from the renewable energy sources. The wide spread distributed energy resources and their variable nature have created the need of integrated regional power grids to make most of the distributed renewable energy resources mix to supply the ever increasing demand of electricity. Pakistan has great potential of wind energy resources near its coastal areas [1]. The huge amount of energy can be transferred from all different parts of the region (energy parts corridors) to the load centres through the integrated regional networks. The implementations of so called 'supergrid' have been proposed for many different regions across the world. The major regional grids proposed are Unified Smartgrid in US, EU Super grid for Europe, DESERTEC for Europe, Middle East and North Africa and SARRC for South Asian countries [2,3]. The major benefits of the regional grid have been listed as:

* Department of Electrical Engineering, Institute of Business Administration, Sukkur.

** Department of Electrical Engineering, Mehran University of Engineering \& Technology, Jamshoro.

Mehran University Research Journal of Engineering \& Technology, Volume 36, No. 1, January, 2017 [p-ISSN: 0254-7821, e-ISSN: 2413-7219] 
- Efficient utilization of natural and renewable energy mix.

- Enhancement of the reliability of the power supply.

- Economical operation and support in contingencies.

- Regional energy security due to regional power grid and fuel diversity.

- Benefits from the seasonal variations in supply and demand.

A Super grid comprises number of the HVDC (High Voltage Direct Current) transmission networks combined to provide reliable and secure power network for multi area interconnection and renewable power integration. The HVDC transmissions are superior to HVAC because of their capability of interconnecting synchronized AC grids and it does not have any stability constraints over the long distance unlike HVAC systems. HVDC has also lower cost and losses as compared to HVAC transmission, as only two conductors are required instead of three for transmitting same amount of power. The breakeven distances are shown in Fig. 1. These are expected to further reduce in near future.

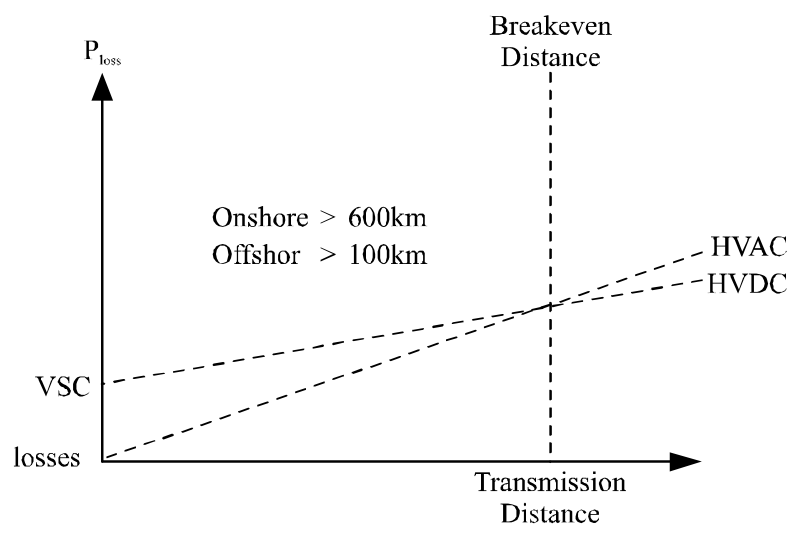

FIG. 1. LOSSES COMPARISON OF HVDC VS HVAC
The VSC based HVDC transmission can be further extended to multi-terminal HVDC (MTDC) systems, which is most suitable for regional power grids. The VSC technology has the capability of multi-directional power flow and independent active reactive power flow control, which makes it capable to be connected to weak or even passive grids $[4,5]$.

New national power system expansion plan up to 2030 has been proposed to coup with current shortfall and future energy demand. The plan shows hydro and thermal coal generation as major contributor and Wind power to replace Thermal-oil generation in long run.

In this paper, keeping in view the benefits of integrated regional power grid, an embedded multi-terminal HVDC meshed grid is proposed for national transmission network of Pakistan, which can be integrated to the future regional (SARRAC) grid. Pakistan being a longitudinal country has longitudinal primary network from South (HUBCO near Karachi) to North (Peshawar) as shown in Fig. 2. The maximum load centres are located at the middle of the country, where no significant generation is possible due to lack of natural resources. The South has predominant thermal power generation with some wind resources planned to be utilized in future and an interconnection with Iran for import of 1000MW power in Phase-I of expansion plan. North has mainly Hydropower potentials with proposed interconnection with Central Asian States (CASA-1000) for import of power [6].

The proposed embedded multi-terminal HVDC based Super grid will enable the transmission of required power to the load centres from the proposed far located generation sites. Further, this paper presents the brief energy balancing mechanism of wind energy and power imports through integration of Super grid in to existing National Transmission System of Pakistan. Dynamic analysis of various control operation has been 
performed on the six-terminal MTDC network in simulation studies to present the advantages of the proposed Supergrid.

\section{IMPLEMENTATION OF THE SUPER GRID}

The longitudinal transmission system of Pakistan requires huge extensions to transfer the power from North and South, where most of generation lies and planned in future, towards the load centres located in the middle of the country. Further, energy imports are suggested from Iran and Tajikistan through interconnections in order to deal with energy shortage on short term basis. These interconnections can be extended to the regional power grids.

Due to afore mentioned advantages of VSC-HVDC over HVAC in long distance transmission, eight major long transmission lines are proposed to be extended as VSCHVDC transmissions with six VSC stations to form an embedded meshed MTDC grid as shown in Fig. 3. Thar Coal converter station (VSC5) has three VSC-HVDC transmission extensions, first connects it to Lahore-South converter station (VSC3), second connects it with Faisalabad-West converter station (VSC5) and third connects it to HUBCO converter station (VSC6). LahoreSouth converter station (VSC3) connects with DiamirBasha-I converter station (VSC1), which further connects to the Peshawar-II converter station (VSC2) and Faisalabad-West converter station (VSC4). Similarly, Peshawar-II converter station (VSC2) connects with Faisalabad-west converter station (VSC4), which further connects with HUBCO converter station (VSC6) and Thar Coal converter station (VSC5). Finally, HUBCO converter station (VSC6) and Thar Coal converter station (VSC5) are connected to each other to form an embedded meshed MTDC grid that encircles the load centre by connecting all major existing and planned generation stations and interconnections from neighboring countries for power import.

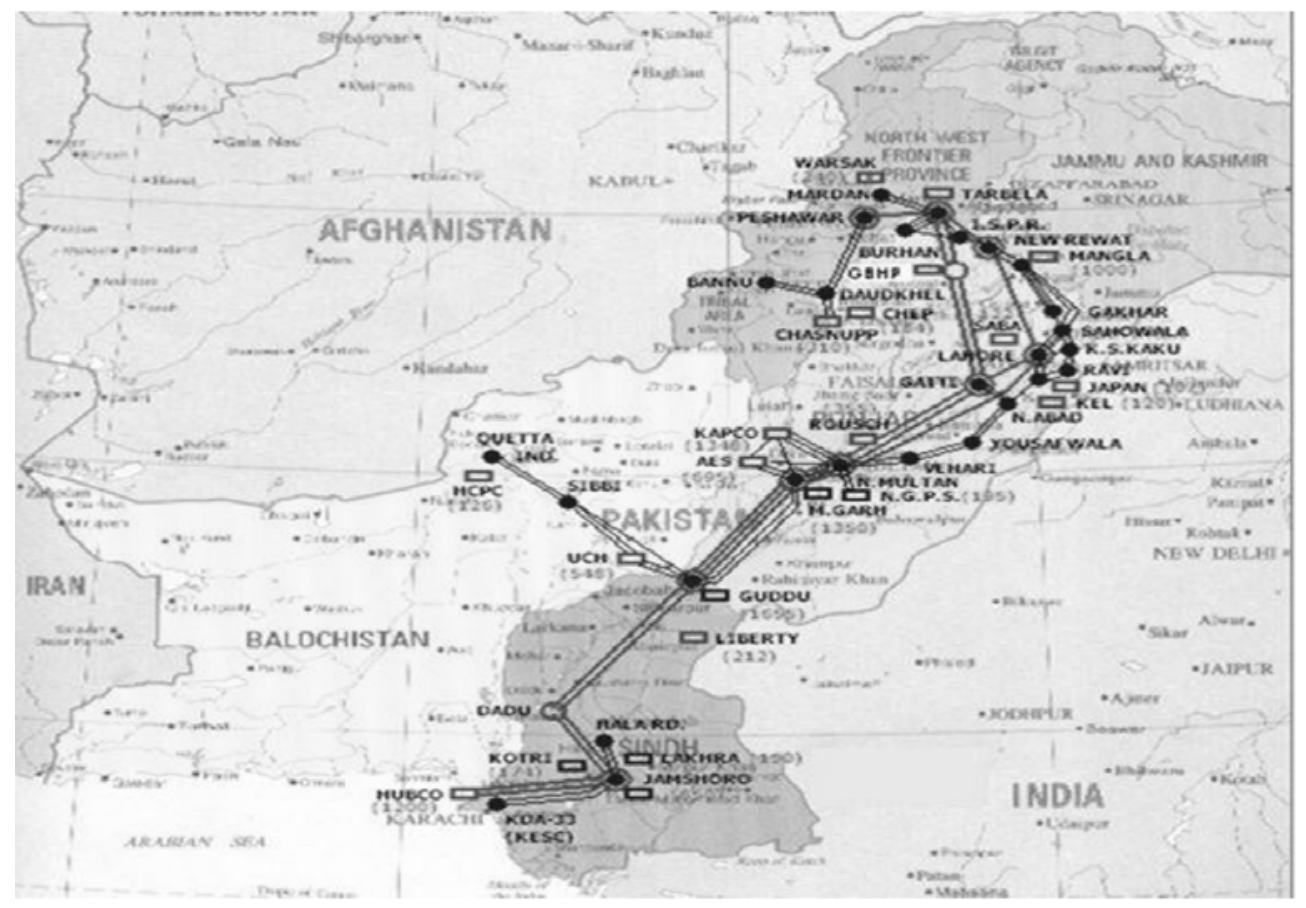

FIG. 2. TYPICAL POWER FLOW CHARACTERISTICS OF NATIONAL TRANSMISSION NETWOR

Mehran University Research Journal of Engineering \& Technology, Volume 36, No. 1, January, 2017 [p-ISSN: 0254-7821, e-ISSN: 2413-7219] 
The radial MTDC grid is suitable for small size networks with limited power transmission requirements, where a single HVDC link can be used to transfer power from small offshore installations or feed offshore Oil \& Gas platforms. In a radial MTDC grid, all the VSC stations are connected to the grid through a single HVDC link. The power sharing and controllability in the radial MTDC grid is easier than in a meshed MTDC grid. The major drawback of a radial MTDC grid is that an outage of the HVDC link will result in the interruption of the whole MTDC grid.

\section{SUPERGRID MODELLING}

\subsection{VSC Modelling}

The average equivalent model of a typical 2-level three phase VSC station is built using equivalent equations of the high power circuit of the VSC in order to avoid the inner VSC switching units. It presents the fundamental frequency equivalent output of the detailed VSC model: this is sufficient to study all the phenomena of the fundamental frequency voltage and current components of the VSC. The outer VSC components (inductors,

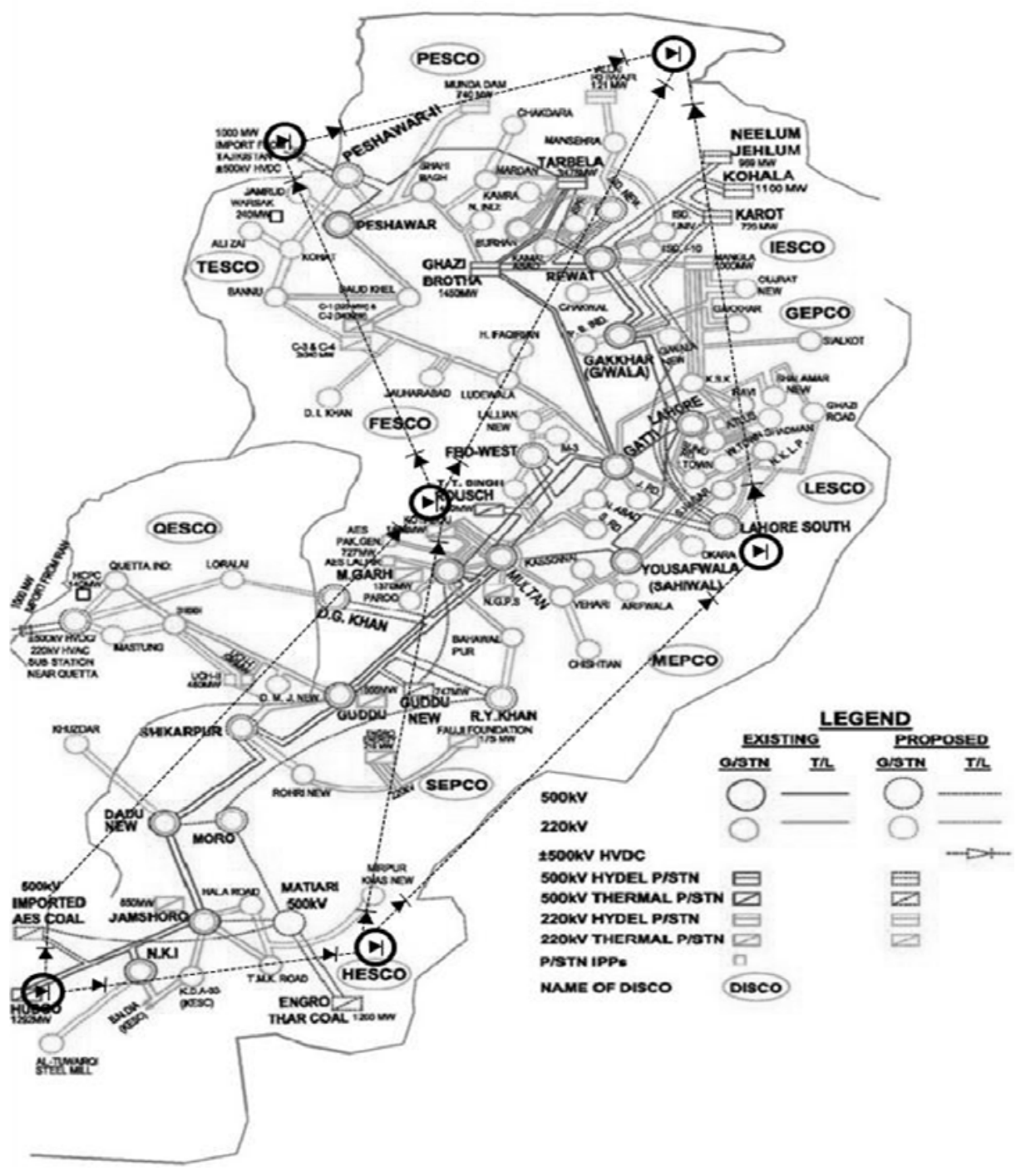

FIG. 3. PROPOSED EMBEDDED MTDC GRID INTO NATIONAL TRANSMISSION NETWORK

Mehran University Research Journal of Engineering \& Technology, Volume 36, No. 1, January, 2017 [p-ISSN: 0254-7821, e-ISSN: 2413-7219] 
cables) and control system dynamics can be fully modelled. The AC side of the VSC is represented as a controllable three phase $\mathrm{AC}$ voltage source and the DC side of the VSC is represented as a controllable current source[7-9].

\subsection{Design and Control of MTDC Systems}

The VSC-based MTDC grid system is interconnected by a HVDC link. The voltage at the DC node is the key indicator for the power balance in the MTDC grid, similar to the frequency for an $\mathrm{AC}$ system. The active power flow through all other terminals needs to be balanced to maintain the DC link voltage within the operating limits for the stable operation of the MTDC grid. In centralized voltage control [10-12], the DC link voltage is controlled by one VSC station, which acts as power slack bus/station (known as master VSC station) in the MTDC grid, while rest of the VSC stations controls the power (regarded as slave VSC station). The N-1 security can be ensured by implementing voltage margin control, in which two VSC stations can control DC link voltage at two different levels, so that in case of failure of master VSC station second can control DC link voltage. The single line representation of VSC station with major components is shown in Fig. 4.

\subsection{Inner Vector Control}

In vector (d-q decoupled) control also known as dq-axis control, the active and reactive power can be controlled independently by using d-q current control strategy which can inherently limit the overloading of switches. Other methods are also suggested for the VSC control in low and medium power applications [13-14].

However, decoupled control is mostly used in the practical application of the VSC transmission and power industry, that is why it is used for inner current controller of the VSC station in this paper. The control configuration of the VSC station based on the decoupled control comprises of cascaded control with faster inner controller and an outer controller which provides reference parameters to the inner controller. The complete diagram of the decoupled control configuration is shown in Fig. 5.

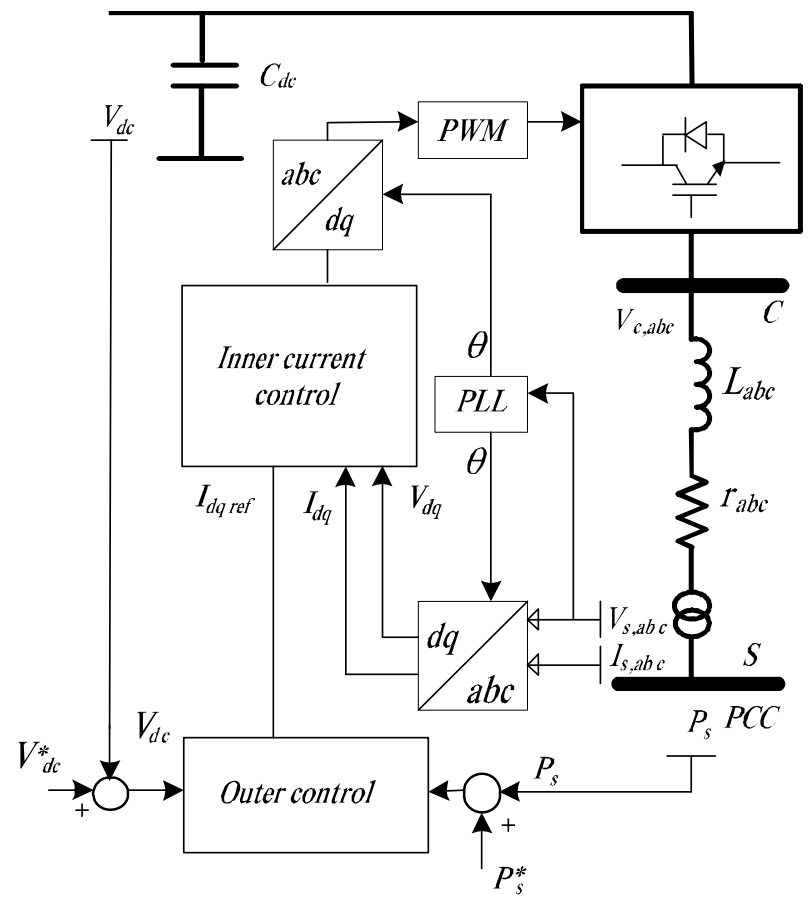

FIG. 5. COMPLETE DIAGRAM OF DQ AXIS VECTOR CONTROL

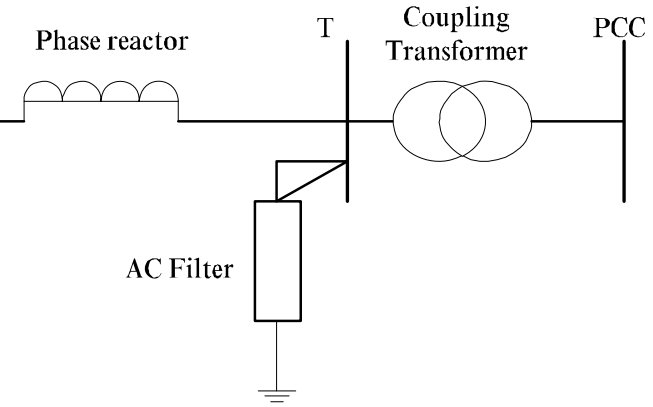

FIG. 4. SINGLE LINE REPRESENTATION OF VSC STATION WITH MAJOR COMPONENTS

Mehran University Research Journal of Engineering \& Technology, Volume 36, No. 1, January, 2017 [p-ISSN: 0254-7821, e-ISSN: 2413-7219] 
The inner dq-control is shown in Fig. 6, which uses the synchronously rotating $\mathrm{d}-\mathrm{q}$ reference frame to transform three phase ac quantities (balanced voltage or current) into equivalent two phase quantities having same resultant space vector to synchronize with AC grid through PLL.

\subsection{Outer Controller of the VSC Station}

The basic operation of outer controller for vector control works similar to the direct control. The vector control can possibly control either active power $\left(\mathrm{P}_{\mathrm{S}}\right)$ or $\mathrm{DC}$ node voltage $\left(\mathrm{V}_{\mathrm{dc}}\right)$ to provide reference for $\mathrm{d}$-axis current $\left(\mathrm{i}_{\mathrm{d}}{ }^{*}\right)$ depending on the DC side network (HVDC link or MTDC grid) requirements of the VSC station.

The apparent power exchange under the dq-axis control can be given as:

$$
\begin{aligned}
& S=\frac{3}{2} V_{s, d q} i_{d q} \\
& S=\frac{3}{2}\left(V_{s, d}-j V_{s, q}\right)\left(i_{d}-j i_{q}\right) \\
& S=\frac{3 s}{2 q}\left(V_{s, d} i_{d}+V_{s, q} i_{i}\right)+j\left(V_{s, q} i_{d}-j V_{s, d} i_{q}\right)
\end{aligned}
$$

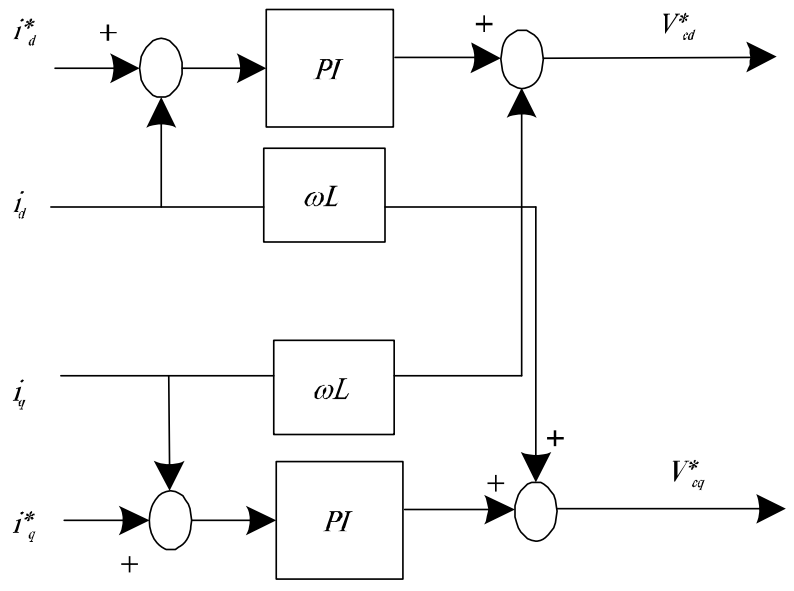

FIG. 6. INNER CONTROL DIAGRAM OF VECTOR CONTROL
Here dq axis is assumed to be aligned with voltage phasor, so Equation (2) and Equation (3) are simplified. The active and reactive power equations can be obtained as:

$$
\begin{aligned}
& \mathrm{P}=\frac{3}{2} \mathrm{~V}_{\mathrm{s}, \mathrm{d}} \mathrm{i}_{\mathrm{d}} \\
& \mathrm{Q}=\frac{3}{2} \mathrm{~V}_{\mathrm{s}, \mathrm{q}} \mathrm{i}_{\mathrm{d}}
\end{aligned}
$$

\subsubsection{Active Power Control}

The Active power control is implemented in order to control the active power through the VSC station to its desired reference value. It uses the PI (Proportional Integral) regulator to eliminate the steady state error as shown in Fig. 7. The output of the active power controller $\left(i_{d}{ }^{*}\right)$ provides reference to $d$-axis of inner current controller and is limited to keep the current through the VSC station within the rated limits.

\subsubsection{Voltage Control}

The DC voltage control of the VSC station is the most important control for stable operation of the VSC transmission as it ensures the power balance through the VSC transmission. The output of the DC voltage controller $\left(i_{d}^{*}\right)$ also provides reference to d-axis of inner current controller, that is why each VSC station can either control Active power or DC voltage. DC voltage control uses the PI control to keep the DC voltage constant by making steady state error zero through the integral gain.

\subsubsection{Reactive Power Control}

Reactive power control by the VSC station can be achieved by implementing a PI regulator. The output of

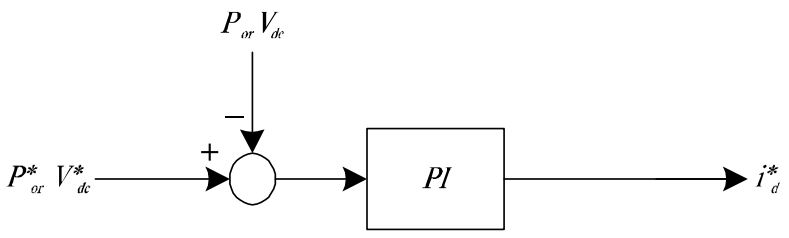

FIG. 7. ACTIVE POWER/ DC VOLTAGE CONTROL 
the DC voltage controller $\left(\mathrm{i}_{\mathrm{q}}{ }^{*}\right)$ also provides a reference to the d-axis of the inner current controller as shown in Fig. 8. The output of the reactive power controller is also limited to maintain the current through the VSC station within the rated limits but with priority to the active power current control.

Due to ability of independent active and reactive power control VSC stations can be connected to very weak AC grids i.e. grids with low SCR (Short Circuit Ratio).

\section{SYSTEM CONFIGURATION}

A proposed six-terminal MTDC grid model has been simulated in EMTDC/PSCAD simulation software as shown in Fig. 9. The sign convention followed in this paper shows power flowing out of the MTDC grid i.e. inverter operation of VSC as positive and power flowing into the MTDC grid i.e. rectifier operation VSC as negative. The VSC2 (Peshawar II-terminal) is set to operate in DC voltage Control mode, whereas the other five VSC stations (VSC1, VSC3, VSC4, VSC4 and VSC6) are set to operate in Power Control mode.

VSC1 and VSC6 are considered to supply 500 and 300MW power into the MTDC grid from the hydel generation and thermal generation respectively, while VSC2 is considered to import 500MW power into MTDC grid from interconnection link with Tajikistan. VSC3 and VSC4 are supposed to supply a constant power of 800 and $900 \mathrm{MW}$ to the load centre from the MTDC grid

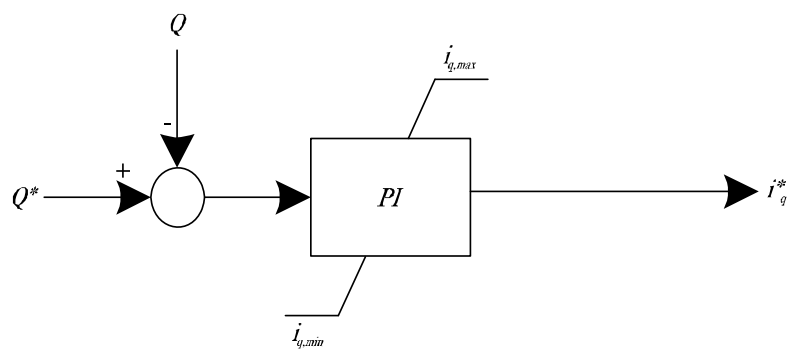

FIG. 8. REACTIVE POWER CONTROL respectively. Whereas, VSC5 is considered to supply 200MW of constant power from the Thar coal generation and $100 \mathrm{MW}$ of variable power from windfarms. The AC grids are represented by their aggregated models.

The parameters used have been inspired from [15-16]: $\mathrm{R}_{\text {cable }}=0.01 \& ! / \mathrm{km}, \mathrm{C}=5 \mu \mathrm{F} / \mathrm{km}, \mathrm{P}_{\text {cRated }}=1000 \mathrm{MW}$ each and $\mathrm{U}_{\text {dcRated }}=400 \mathrm{kV}$ each. The approximate lengths of the cables are taken as; $1_{12}=475 \mathrm{~km}, 1_{14}=980 \mathrm{~km}, 1_{13}=620 \mathrm{~km}, 1_{35}=520 \mathrm{~km}$, $1_{24}=1100 \mathrm{~km}, 1_{46}=450 \mathrm{~km}, 1_{45}=535 \mathrm{~km}$ and $1_{56}=420 \mathrm{~km}$.

\section{SIMULATION AND RESULTS}

The Super grid model simulations are performed following pu (per unit) method based on the rated power and voltages of the VSC stations described in earlier section.

Two different scenarios of proposed Super grid have been simulated; one without integrating any wind energy generation and the other with integrated wind energy generation to present the energy balance mechanism that can be achieved by the Super grid controlled operation. Some variation in the power from the wind power generation have been simulated to demonstrate the power balance mechanism of the Super grid system under wind variations.

Scenario-I: In the first scenario power supply from all the VSC is constant, since no power from the windfarm is introduced. The simulation results in Fig. 10 show that a constant power of 0.8 and 0.9 pu being supplied to the VSC3 and VSC4 respectively from the MTDC grid by taking in 0.5, 0.2 and 0.3pu from VSC1, VSC5 and VSC6, respectively. While VSC2 imports in the difference between the source and the load i.e. 0.7 pu power into the MTDC grid, to maintain a constant DC link voltage of 1 pu at its terminal of the MTDC grid. 
Scenario-II: In the second scenario, the control configuration of the MTDC grid is same but variable power from the windfarm is introduced at the VSC5. As shown in Fig. 11, a windfarm start to add 0.1 pu power in to MTDC grid at $\mathrm{t}=2 \mathrm{~s}$ and another $0.1 \mathrm{pu}$ ate $\mathrm{t}=6 \mathrm{~s}$. A steady increasing can be seen 2-3 seconds with sudden change at $\mathrm{t}=6 \mathrm{~s}$ from VSC5. While power import from the VSC2 can be seen as reducing consequently with the increase of power from the windfarms.

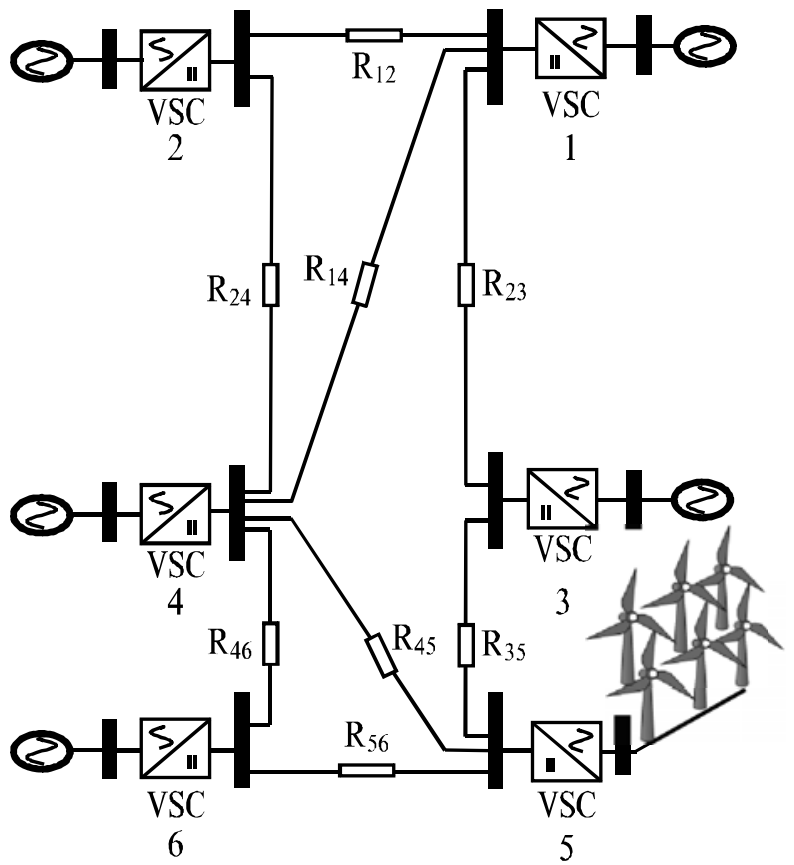

FIG. 9. PROPOSED SIX-TERMINAL VSC-MTDC SYSTEM FOR NATION TRANSMISSION EXPANSIO
However, when windfarms get completely disconnected at $\mathrm{t}=8 \mathrm{~s}$, power form the VSC5 reduces back to $0.2 \mathrm{pu}$ and VSC2 again start to import $0.7 \mathrm{pu}$ power into the MTDC grid to maintain constant the DC link voltage at $1 \mathrm{pu}$ as shown on Figs. 12-13.

\section{CONCLUSIONS}

The future power networks are required to be highly flexible and adaptive to respond the variation of power, due to shift of centralized constant energy generation from conventional resources to variable distributed generations from renewable sources. The Super grid models are proposed for the continental regional grids around the world.

This paper proposed a Supergrid model for the National Transmission Network of Pakistan, to utilise the efficient energy mix of wind energy resources available in Pakistan. The dynamic simulations performed shows Super grid model can provide efficient transmission between generation and load centres and is also adaptive to deal variation in power from renewable generations. Further, advanced distributed controls such as DC voltage droop control, autonomous control, active-band control and triband control can also be implemented on proposed Super grid model.

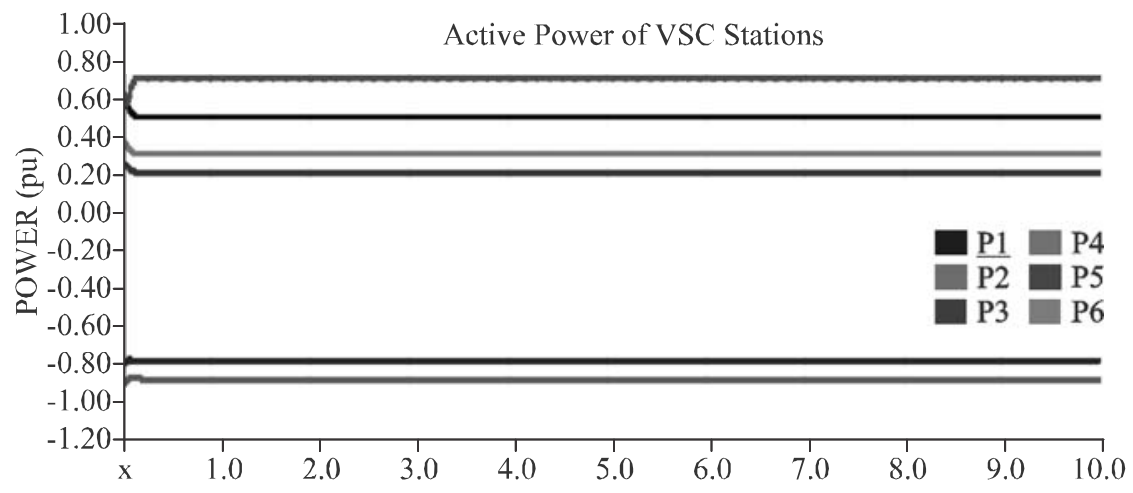

FIG. 10. ACTIVE POWER FROM THE VSC STATIONS IN THE MTDC GRID UNDER SCENARIO I 


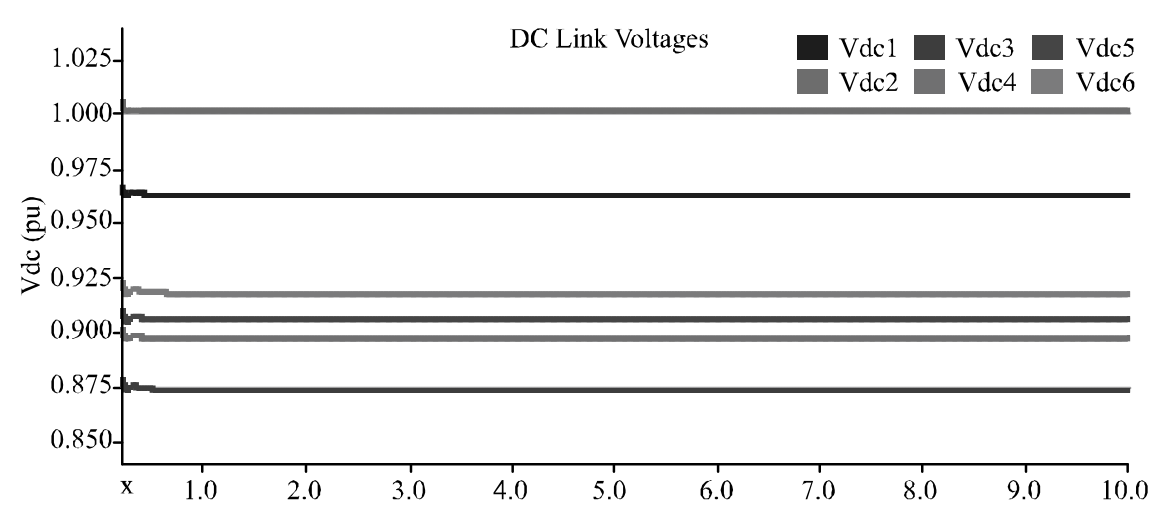

FIG. 11. DC LINK VOLATGE OF THE VSC STATIONS IN THE MTDC GRID UNDER SCENARIO-I

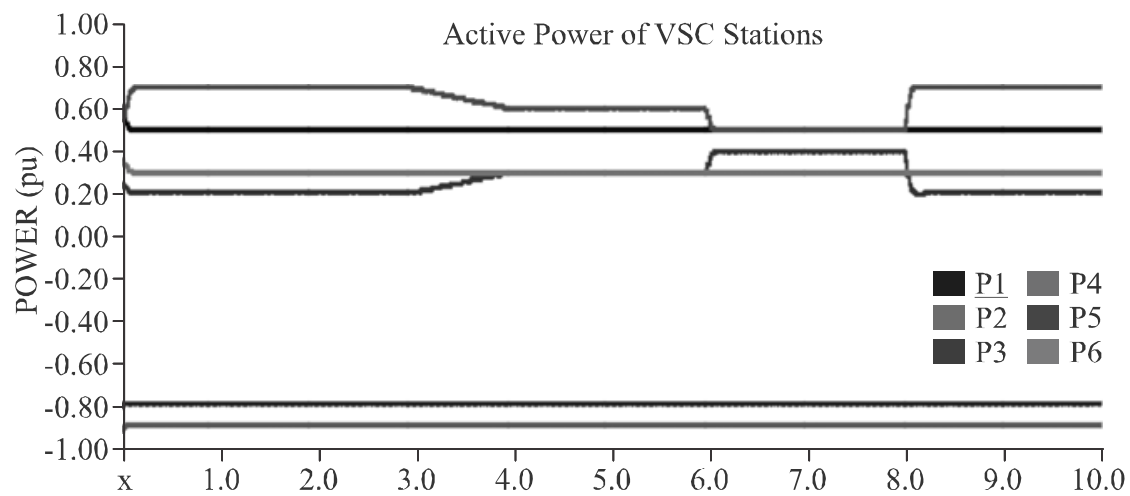

FIG. 12. ACTIVE POWER FROM THE VSC STATIONS IN THE MTDC GRID UNDER SCENARIO-II

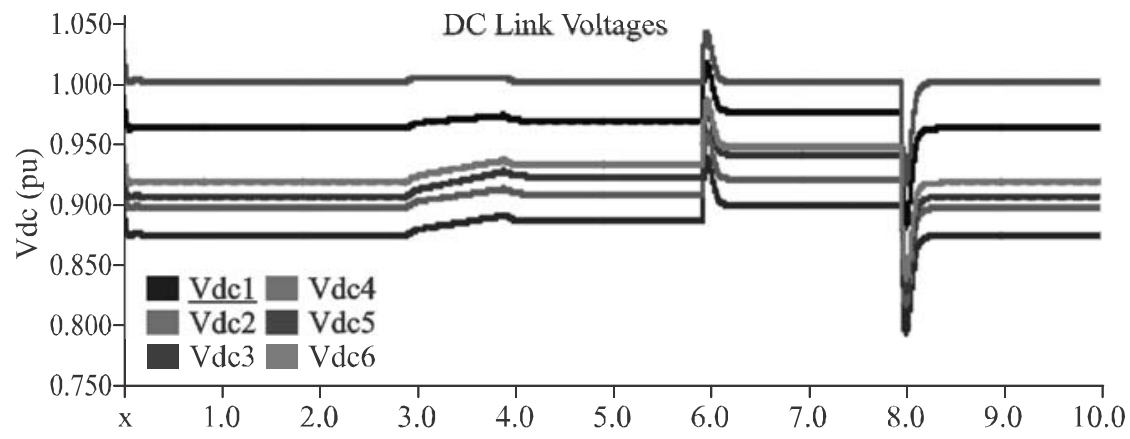

FIG. 13. DC LINK VOLATGE OF THE VSC STATIONS IN THE MTDC GRID UNDER SCENARIO-II

\section{ACKNOWLEDGEMENTS}

First author would like to acknowledge the affiliation and funding resources for this research from Sukkur Institute of Business Administration, Sukkur, and Mehran University of Engineering \& Technology, Jamshoro, Pakistan.

\section{REFERENCES}

[1] Akhter, F., Macpherson, D.E., and Shahzad, N., "Impact of Wind Integration on National Transmission Network", Communication Technology Information Security Sustaintable Devevelopm, Volume 414, pp. 13-23, 2014. 
[2] Rashid, T.H.M.S., and Islam, R., "Prospects of Renewable Energy Resources and Regional Grid Integration for Future Energy Security \& Development in SAARC Countries", Internatonal Journal Research Engineering Technology, pp. 43-51, 2013.

[3] Airtricity, "European Offshore Supergrid Proposal: Vision and Executive Summary", 2010.

[4] B4-WG.37, "VSC Transmission", International Conference on Large High-Volatge Electrical System, Volume CIGRE, 2005.

Akhter, F., Macpherson, D.E., and Harrison, G.P., "Enhanced Multi-Terminal HVDC Grid Management for Reliable AC Network Integration", 7th IET International Confernece on Power Electronnic Machanics Drives, pp. 0495-0495, 2014.

Report, R., "National Power System Expansion Plan Excutive Summary", 2011.

CIGRE Working Group B4.52, "HVDC Grid Feasibility Study", 2013.

Peralta, J., Saad, H., Dennetière, S., and Mahseredjian, J., "Dynamic Performance of Average-Value Models for Multi-terminal VSC-HVDC Systems", IEEE Power and Energy Society General Meeting, pp. 1-8, 2012.

Moustafa, M.M.Z., "Operating Limits and Dynamic Average-Value Modelling of VSC-HVDC Systems", University of Manitoba, 2011.

[10] Nakajima, T., and Irokawa, S., "A Control System for HVDC Transmission by Voltage Sourced Converters", Power Engineering Society Summer Meeting, pp. 1113-1119, 1999.
[11] Lu, W., and Ooi, B.-T., "Optimal Acquisition and Aggregation of Offshore Wind Power by Multiterminal Voltage-Source HVDC", IEEE Transactions on Power Delivery, Volume 18, No. 1, pp. 201-206, 2003.

Zhu, J., and Booth, C., "Future Multi-Terminal HVDC Transmission Systems using Voltage Source

Converters", 45th International Conference on Universities Power Engineering, pp. 1-6, 2010.

[13] Malesani. L., and Tomasin, P., "PWM Current Control Techniques of Voltage Source Converters - A Survey", IEEE 19th Annual Conference on Industrial Electronics, pp. $670-675,1993$.

[14] Ooi, B.T., and Wang, X., "Voltage Angle Lock Loop Control of the Boost type PWM Converter for HVDC Application”, IEEE Transactions on Power Electronic, Volume 5, No. 2, pp. 229-235, April, 1990.

[15] Haileselassie, T.M., and Uhlen, K., "Precise Control of Power Flow in Multiterminal VSC-HVDCs using DC Voltage Droop Control”, IEEE Power Energy Society General Meeting, pp. 1-9, July, 2012.

[16] Akhter, F., Macpherson, D.E., Harrison, G.P., and Bukhsh, W.A., "DC Voltage Droop Control Implementation in the AC/DC Power Flow Algorithm: Combinational Approach", IET 11th International Conference on AC and DC Power Transmission, pp. 1-6, 2015. 